\title{
The need for a long-term mindset when measuring the effects of lean on health-related quality management values \\ A case study from the public sector
}

\author{
Pernilla Ingelsson and Ingela Bäckström \\ Department of Quality Technology and Management, Mid Sweden University, \\ Östersund, Sweden
}

Effects of lean on health-related QM values

Received 18 August 2015 Revised 10 February 2016 23 November 2016 8 March 2017 Accepted 20 March 2017

\begin{abstract}
Purpose - The purpose of this paper is to investigate the effects a lean initiative has on the health-related quality management (QM) values, "Leadership Commitment" and "Participation of Everybody," as well as on perceived co-worker health in the public sector.

Design/methodology/approach - A case study was carried out at a municipal division that had been working with lean for approximately 18 months. A questionnaire was used to measure the effect on health-related QM values both before and after the initial 18 month period. Documents from the intended lean implementation were studied at the starting point and after 18 months; this was followed up by examining new documents. The results from the questionnaires were analyzed using SPSS and the documents were analyzed by means of document comparisons and consensus discussion in the research group.

Findings - The effects on the health-related QM values; "Leadership Commitment" and "Participation of everybody" in this study showed that the values still permeated the organization to a relatively high extent after 18 months but that no statistical differences can be shown between the two measurement points. When measuring what effects a lean initiative has on values, a period of 18 months might be too short, if significance changes are expected. None the less, the results can be a way of monitoring the development of these softer values. Something that is equally important is to see if there have been any major changes, as a way of keeping the work with building a new culture alive and in focus. The results strengthen the assumption that a long-term mindset is needed when QM initiatives such as lean are applied within an organization especially when changes to values and workplaces are expected.
\end{abstract}

Originality/value - This study has further explored the QM in relation to lean in the respect of how the QM values "Leadership commitment" and "Participation of Everybody" are effected by a lean initiative.

Keywords Quality management, Co-worker health, Leadership commitment, Lean initiative,

Participation of everybody, Workplace health and soft values

Paper type Research Paper

\section{Introduction}

During the last few decades, management concepts such as lean production and total quality management (TQM) have been used to promote changes and development toward business excellence, see for instance (Zwetsloot and Pot, 2004; Docherty, 2002). TQM is "a management approach of an organization, centered on quality, based on the participation of all its members and aiming at long-term success through customer satisfaction, and benefits to all members of the organization and society" (Dale, 2003). The values that are frequently raised in quality management (QM) literature are: customer orientation, leadership commitment, participation of everybody, continuous improvements, management by facts and process orientation (Sila and Ebrahimpour, 2002). One QM initiative that is gaining a lot of attention both from practitioners and researchers is lean. Lean is said to have the same origins as TQM (Dahlgaard and Dahlgaard-Park, 2006) and has become a widely spread concept in many different types of organizations. Even though lean originates from the automotive industry, it can be appropriate for other kinds of

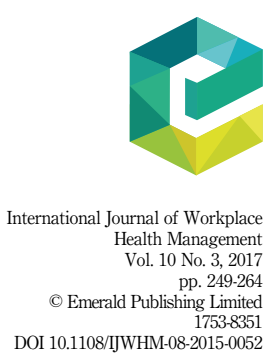


IJWHM 10,3

organizations, for instance healthcare (Poksinska, 2010; Mazzocato et al., 2010), education (Emiliani, 2005) and public service (Radnor et al., 2006). According to, e.g. Womack and Jones (2003) and Liker (2004) lean focuses on maximizing customer value and minimizing different kinds of waste. Bicheno and Holweg (2009) states that there is a need for creating a culture based on values like long-term thinking, a system view and continuous improvements and in order to achieve this, a number of methods and tools are used, e.g. value flow analysis, standardization, $5 \mathrm{~S}$, etc. However, the most important thing is to first stand back and look at the system and then apply the thinking adjusted to the organization's prerequisites (Bicheno and Holweg, 2009).

Criticism has been raised against lean and its effect on the working environment. Hasle et al. (2012) reviewed 11 articles covering the quantitative effects of lean in manufacturing and analyzed these in order to extract information on the effects it has on the working environment. They found that most of the studies showed negative effects but since some showed positive effects they conclude that there is a need to understand lean as an "open and ambiguous concept." The effects can be both positive and negative depending on how lean is practiced within the organization (Hasle et al., 2012, p. 829). The studies reviewed by Hasle et al. (2012) were done on auto industries, other manufacturing industries or service industries like call centers and none on the effects on health when implementing lean in the public sector. According to the Official Reports of the Swedish Government, SOU (2013, p. 40) Sweden has in many ways an efficient public sector but there are also many challenges. Challenges in terms of, for instance, a declining confidence in public institutions, long-term financing of health and social services and a skewed demographic (SOU, 2013, p. 40). These challenges lead us to believe that there is a need to do more with public sector, rather than just making minor improvements: there seems to be a need for a deeper systemic change in this sector. Nordin and Bolin (2014) suggest that a promotive perspective can decrease sickness absence and protect organizations and society from costs due to sick leave and loss of productivity and that it is possible to enhance the co-workers' working conditions and their health through improvement strategies (Bolin, 2009). Zwetsloot et al. (2010) agree and state that a predominant assumption in literature is that investments in health can lead to organizational benefits since healthier co-workers are more productive. Since bad health not only means suffering for individuals but also has implications on their performance and capacity to work and be productive (Arnetz, 2005), this is an important factor to take into consideration when applying different $\mathrm{QM}$ initiatives.

Commitment to quality by both the individual and the organization are two key areas that should be assessed at the beginning when implementing TQM (Beatty, 2006). This is in line with Hansson (2003) who found that committed leadership and the participation of the co-workers were important fundamentals for successful implementation of TQM. But, at the same time, several researchers claim that TQM initiatives are frequently not fully applied; see, for instance, Hansson (2003) and Harnesk and Abrahamsson (2007). Research by Wreder (2006) shows that a QM strategy based on a culture of core values improves co-worker health and one study points to the commitment of managers as the most central of the common factors for achieving a healthy work place as well as creating efficient organizations (Lagrosen et al., 2007). According to Bäckström (2009) and Lagrosen et al. (2012), the values "Leadership Commitment" and "Participation of Everybody" are important to support sustainable health among co-workers when QM is practiced. Additionally, the factors of continuous improvement, participation of everybody, information and customer orientation were found to be, in certain instances, related to co-worker health status and/or successful QM implementation (Lagrosen et al., 2012).

Lean is seen as being founded on a number of principles or values (Liker, 2004; Womack and Jones, 2003; Emiliani, 2010). These values should be present and shared by the members of an organization for lean to be successfully applied (Achanga et al., 2006; Bhasin and Burcher, 2006). 
Liker (2004) states that applying lean needs a deep cultural transformation and according to Emiliani (2010) the only way to achieve what he calls real Lean is if the two main values "continuous improvement" and "respect for people" permeate the organization. The managers have to act as role models to reinforce the culture by demonstrating the behaviors they themselves request from their co-workers (Ingelsson, 2013). According to Dale (2003), there seems to be a need for information and guidance on how to make a cultural change in an organization, even though changing the organizational culture is mentioned as an important factor when applying different QM initiatives. In relation to this, there is also a need to measure the effects on values and culture when using different QM initiatives, i.e. softer measures (McNabb and Sepic, 1995; McAdam and Bannister, 2001; Ingelsson et al., 2010).

In accordance with these suggestions, the purpose of this paper is to investigate the effects a lean initiative has on the health-related QM values, "Leadership Commitment" and "Participation of Everybody," as well as on perceived co-worker health.

\section{Lean as a $\mathrm{QM}$ initiative}

Many QM initiatives are said to be built on values and the need to address the organizational culture when applying different QM initiatives is something many agree upon (see e.g. Achanga et al., 2006; Yamamoto and Bellgran, 2010; Bhasin and Burcher, 2006). If an organizational culture is to be considered strong, the co-workers within the organization need to share the same values (O'Reilly et al., 1991). A strong culture is created by a high level of agreement among employees about what is valued and a high level of intensity about these values (Chatman and Cha, 2003). According to Grönfeldt and Strother (2006), a strong culture energizes the employees by appealing to higher ideals and undefined values and shapes and coordinates behaviors and decisions and thereby improves the performance of the organization. Hendricks and Singhal (1999) believe that if TQM is to be applied effectively the values need to be well accepted, practiced and deployed within an organization. To achieve a successful lean transformation the need for a shared value base is just as important as within TQM (Ingelsson et al., 2010). An important factor for achieving a sustainable lean initiative "is to build a supporting culture and system that guides the behavior and thinking of the employees" (Poksinska et al., 2013, p. 897). This in turns entails leaders leading by example and acting as culture carriers (Poksinska et al., 2013, p. 897). Lean leaders' most important task is to influence co-workers and this requires strong transformational leadership skills and behaviors (Poksinska et al., 2013, p. 897).

Commitment is conditional within a lean initiative but is neither inherently supported nor naturally impended by lean production (Angelis et al., 2011). The commitment is instead dependent on managers' effectiveness in designing and operating the lean initiative (Angelis et al., 2011). The role of managers in organizations that have implemented lean is changing from managing processes to managing people with a focus on motivating, coaching and developing individuals and teams (Poksinska et al., 2013). The leaders use a coaching leadership style to develop employees and encourage cooperation and responsibility (Poksinska et al., 2013). The lean leaders' managerial work is focused on creating a learning and facilitative work environment and the leaders pay considerable attention to employees' needs and their development (Poksinska et al., 2013). Poksinska et al. (2013) conclude that lean leadership is a central aspect in a lean initiative together with continuous attempts to achieve the lean transformation.

According to Sinkula et al. (1997), creating a shared understanding of the organization's vision and values is a long-term process even though modifications of organizational structures can be done rather quickly. Lean is not an isolated program but, like TQM, a never-ending process or journey (McAdam and Bannister, 2001; Drew et al., 2004; Bicheno, 2004). Implementing lean needs a deep cultural transformation rather than simply implementing a set of lean tools according to Liker (2004) which makes it a long-time commitment.
Effects of lean on

health-related QM values 
IJWHM 10,3

Building organizational culture takes time and requires of leaders an understanding about how to build systems of communication that support shared values and a collective vision (Snyder et al., 2000). Bhasin and Burcher (2006) claim that a medium-sized company will need a minimum of three to five years to start practicing a lean philosophy and for a successful implementation lean needs to be viewed as a long-term journey and the organizations need to make numerous cultural changes. According to Emiliani (1998), the practice of sustained lean behaviors will take five to ten years for an organization.

Lean thinking can be seen as a part of a larger management change in order to plan for a shift in mindsets and workplaces (Emiliani, 1998). Radnor and Boaden (2010) claim that lean is just another organizational change initiative which represents another opportunity for the public sector to understand the process of change. When applying lean, substantial cost savings and quality improvement can be achieved (Radnor and Walley, 2008). After studying results from lean in the public sector, Radnor et al. (2006) conclude that the success of lean is dependent on organizational and cultural factors. Lean in the public sector should be about adaptation rather adoption without adaptation (Radnor and Boaden, 2010). In addition, the reason why organizations have chosen to apply lean has a profound effect on what will be focused on (Emiliani, 2010). The focus should be on the benefit to the customer, not on internal company reasons (Emiliani, 2010). Regardless of the fact that the main reasons for applying lean are cost reduction, less defective parts and improvement of delivery reliability (Peter and Lanza, 2011). Brännmark (2012) concludes, after a review of existing empirical research literature on how lean is used in municipalities and governments, that there is a need for more research. He found 17 articles that were relevant but that the empirical evidence was thin and that the included studies were of widely varying quality and design. He claims, for instance, that there is a need for more longitudinal studies since they are missing and also more studies on how co-workers are effected by lean in the public sector (Brännmark, 2012).

\section{QM initiatives and co-worker health}

According to Hughes (2007), work-life balance has a major impact not only on business productivity but also on the economy as a whole. Wolf (2008) states that there are enormous consequences for the workplace as mental illness goes hand in hand with significant productivity losses. According to Janssen et al. (2003), the occurrence and causes of sickness absence are affected by several factors, many of which are work-related and organizational. Marklund et al. (2008) maintain that co-worker health is usually indirectly, but not directly, determined by organizational characteristics. The link is indirect in the sense that working conditions that affect health are related to organizational factors, and health itself has a more complex causal connection.

When QM is practiced, the value "Leadership Commitment" and the value "Participation of Everybody" are central to the support of health among co-workers (Bäckström, 2009; Lagrosen et al., 2012). The underlying dimension of these health-related QM values was examined by Lagrosen and Bäckström (2005) and Lagrosen et al. (2010). They pointed out that integrity, presence and communication, empathy and continuity are underlying dimensions of "Leadership Commitment" and that development, being informed and influence are underlying dimensions of the value "Participation of Everybody." When successful organizations that had achieved good workplace health were investigated, these underlying dimensions were found to be present as established methodologies, values and practices (Bäckström, 2009).

Hasle et al. (2012) showed in their literature review that, out of the 11 studies they analyzed, nine included information about health and well-being and lean. Out of these, seven showed primarily negative effects and two showed both negative and positive effects. Even though the result did not show a distinct causal relationship, lean definitely affects the 
working environment and health and well-being and it would appear that it influences them in a number of ways. They state that it seems that the effect is more a result from the implementation process and the context in which lean is being implemented (Hasle et al., 2012). Bäckström and Ingelsson (2015) found a positive correlation between the co-workers' perception of their health and lean leadership and lean values in their study at a municipality. When examining QM in relation to lean and from both a worker health and safety and operational performance perspective, Longoni et al. (2013) conclude that QM needs to be further explored in relation to the wider lean context.

Hasle et al. (2012) also found that employee involvement has proven to have a positive effect on the working environment, something that is reinforced by Koukoulaki (2014). Co-workers' well-being depends largely on the leaders' choices in designing a lean initiative (Conti et al., 2006). A lean initiative is neither intrinsically stressful for the co-workers nor predetermined to affect co-workers' well-being: everything depends on the leaders' way of acting (Conti et al., 2006).

A literature review examining the impact of lean on both musculoskeletal and psychosocial risks, covering a period of 23 years, found reports on negative effects on workers associated with some lean practices, such as Just-In-Time and standardized work (Koukoulaki, 2014). The review shows that the harmful results are more evident in automotive industries and that in service and other sectors the outcome is more balanced. Koukoulaki (2014) further states that the view on lean as being an inherently harmful management system has evolved into it being perceived as a system that can have varied effects depending on how it is being implemented as well as the management style. We see lean as a QM initiative which can be a part of a culture change when the purpose is to shift mindsets. The initiative can affect the co-workers' well-being in a positive way, but this is dependent on how the leaders are acting.

\section{Measuring the effects of a $\mathrm{QM}$ initiative}

When measuring the effect of a QM initiative, the framework should include hard and soft measures and should include perceptive data from co-workers (McAdam and Bannister, 2001). The management literature encourages the use of soft measures in the study of organizational quality improvement according to Louise (1996), and she maintains that those measurements can be used for a great variety of purposes both for monitoring or to include cultural change. Many mention the need to develop a performance measurement system that consists of hard data outcomes and soft measures found in organizational culture, including values, norms and behaviors (Kollberg et al., 2007; Snyder et al., 2016). There is a need to study soft measures at the beginning of a new management initiative in order to capture baseline data linked to the values currently held by the managers and co-workers (McNabb and Sepic, 1995).

The focus when measuring organizational effectiveness and success has usually been on financial figures or hard measurements such as cost of quality, reduced inventory and delivery dependability (Motwani, 2001). Saad and Patel (2006) agree that the measurements have fundamentally been focused on tangible and financial factors and that there have been insufficient attempts to measure the performance at inter-organizational level.

Shah and Ward (2007) argue that it is often difficult to measure lean production directly due to the fact that it is conceptually multifaceted, and its definition spans philosophical characteristics. Many organizations have been relying on performance measures to demonstrate success, not recognizing the importance of building a culture that supports the lean journey (Ahmed, 2013; Halling and Wijk, 2013). According to Petersen and Wohlin (2011), there exist a number of lean process measures for manufacturing but measuring productivity is rather different when it comes to non-manufacturing organizations (Hamid et al., 2011). The analysis and development of lean in public services are an interaction of practice and theory and it is vital that this continues to be so (Radnor and Boaden, 2010).

Effects of lean on health-related QM values 
IJWHM 10,3
Emiliani (1998) believes that the catalyst for further improvement in organizations is the practice of lean behaviors, performance by elimination of waste within functions and by the sustaining of internal and external boundaries. Before removing the waste and improving the flow, it is central to understand the current status in terms of waste and flow and that this is best carried out through visualization and measuring (Petersen and Wohlin, 2011). In the public sector lean adaption should initially engage with the principles of customer and process view, flow and reduction of waste through the use of simple tools and techniques instead of embarking on the implementation of the more complex tools used in manufacturing (Radnor and Boaden, 2010). To accomplish this Radnor and McGuire (2004) claim that there has to be an understanding of the relationship between strategy, people, organizational form/design and performance systems. When assessing the efficiency and effectiveness of the quality initiative it is important to understand the performance (Radnor and Barnes, 2007). Efficiency focuses on measures regarding the productivity of a process, while effectiveness focuses on the notion of the appropriateness of the outputs of the process, which is a broader set of measures (Radnor and Barnes, 2007). When measuring effectiveness, the emphasis should be on softer measures such as levels of innovation, motivation and customer retention (Radnor and Barnes, 2007). The evidence of concrete benefits from lean implementation in the public sector is not always as clear-cut as in the manufacturing sector (Radnor and Boaden, 2010). Concrete benefits include a better understanding of customers, cross-team synergies, and an increase in co-worker motivation and morale (Radnor and Boaden, 2010).

It is vital to design a measurement system that reflects the QM initiative taken when a new management implementation, such as applying lean thinking principles, is carried out (Kollberg et al., 2007). Many managers attempt to apply lean without fully understanding its underlying principles which results in nothing but the creation of a set of tools and techniques rather than a central shift in culture and approach (Radnor and Boaden, 2010). As the failure to create a shared value base is pointed out as one main reason for lack of success in applying TQM and lean (Ingelsson et al., 2010), it is vital to measure these values. However, the measuring of values and organizational culture, e.g. the soft side, appears to be missing within both concepts (Ingelsson et al., 2010). There are though some questionnaires and measurement approaches that measure the existence and the importance of QM and lean values and culture within an organization (Ingelsson et al., 2010; Lagrosen et al., 2012; Ingelsson, 2013).

\section{Measuring health-related $\mathrm{QM}$ values}

As mentioned earlier, Bäckström (2009) and Lagrosen et al. (2012), found that the values "Leadership Commitment" and "Participation of Everybody" are important to support sustainable health among co-workers when QM is practiced. Further research examining the content of these values revealed the seven underlying dimensions of which they consist (see Figure 1) (Lagrosen et al., 2010).

Empathy, the first underlying dimension, implies that the managers must show awareness and concern and must be alert to the needs of the co-workers and understand their situation. Presence and communication, the second underlying dimension, implies that the managers practice visible leadership and communicate clearly and distinctly. The third underlying dimension, integrity, deals with the manager's own characteristics such as independence, trustworthiness and fairness. Continuity is the fourth underlying dimension of the value "Leadership Commitment" which means that the manager should stay in the same position for a long time (Lagrosen et al. 2010) (Figure 2).

The first underlying dimension of the value "Participation of Everybody," influence is about co-workers' possibility to influence their own work situation. In the second underlying dimension, development, both skills and personal development are included. 
Common values within QM

Values important to co-worker health

Underlying dimensions within those values

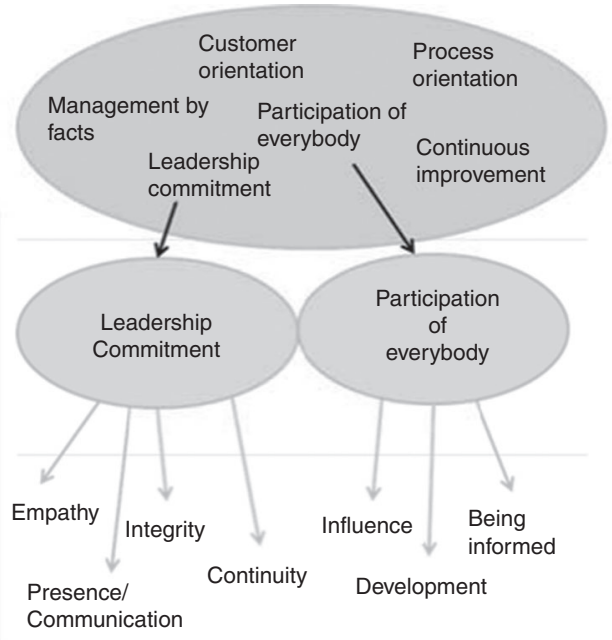

Effects of lean on health-related QM values 255

Figure 1. The relationship between $\mathrm{QM}$ values and underlying dimensions affecting

co-worker health, designed after Lagrosen et al. (2010, 2012)

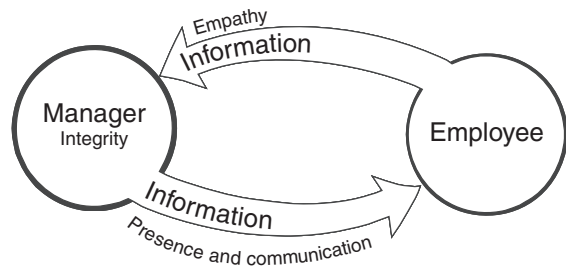

Continuity

Source: Lagrosen et al. (2010)

Figure 2.

A model of the dimensions of "leadership commitment" - the manager's perspective

The third and last underlying dimension is being informed and considers communication in general and especially getting enough information. It is important that the managers communicate with all co-workers (Lagrosen et al., 2010) (Figure 3).

Based on this research, a measurement approach, in the form of a questionnaire, was developed in order to help managers examine to what extent the two health-related QM values permeated their organization (Lagrosen et al, 2012). Each dimension in the questionnaire was constructed by means of three different statements that represent the specific dimension based on earlier research. The respondents were asked to mark on a seven-point agreement scale to what extent they agreed with the statements (Lagrosen et al, 2012). The questionnaire has then been used and tested with its original design in eight elementary schools (Bäckström et al, 2012; Bäckström, Lagrosen and Eriksson, 2014)

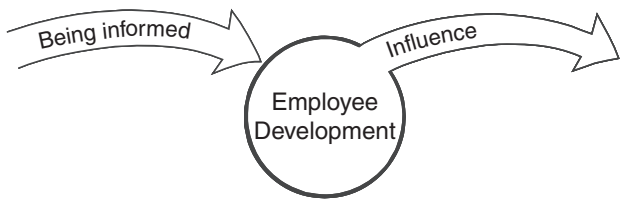

Figure 3. A model of the dimensions of "participation of everybody"

Source: Lagrosen et al. (2010) 
IJWHM 10,3

256

in a municipality division (Bäckström et al, 2012) and in two preschools (Åslund et al, 2011). The statements for the health-related values "Leadership Commitment" and "Participation of Everybody" together with statements for lean values have been used in two manufacturing companies where the underlying dimensions were tested (Ingelsson and Bäckström, 2016). The questionnaire can also be used to point out to what extent the organization is practicing the health-promoting values of QM and in which areas improvement is needed to increase co-worker health (Bäckström, 2009; Lagrosen et al, 2012). The questionnaire can also be used longitudinally to assess status before and after carrying through an organizational change (Lagrosen et al, 2012). The questionnaire has been used to evaluate health-promoting activities (Bäckström et al, 2012) and to measure the effects of an initiative based on appreciative leadership (Åslund et al., 2011). The dimensions of health-related QM values has been analyzed vs key principles of communicative leadership with results showing there are relations between the two (Bäckström, Ingelsson, and Johansson, 2014). Another study showed that managers view of communicative leadership support most of the underlying dimensions of health-related QM values (Bäckström et al., 2016).

\section{Methodology}

In order to investigate the effects a lean initiative has on the health-related QM values as well as perceived co-worker health, a case study was carried out at a municipal division which had chosen to implement lean. A case study was suitable since the organization wanted to measure the effect on co-worker perceived health when implementing lean. The underlying dimensions of the health-related QM values and the health index were measures to investigate if the lean initiative had affected these values. The starting point conditions were measured by means of the questionnaire described above which measured health-related QM (Lagrosen et al, 2012). A follow up measurement was then carried out 18 months later. In addition, documents relating to the lean implementation were studied at the starting point. After 18 months this was followed up by examining new documents and also by a telephone interview with the person responsible for the lean implementation in order to get an accurate timeline for the implementation process at the division (see Figure 4).

Figure 4.

Activities carried out to implement lean within the service and technical division

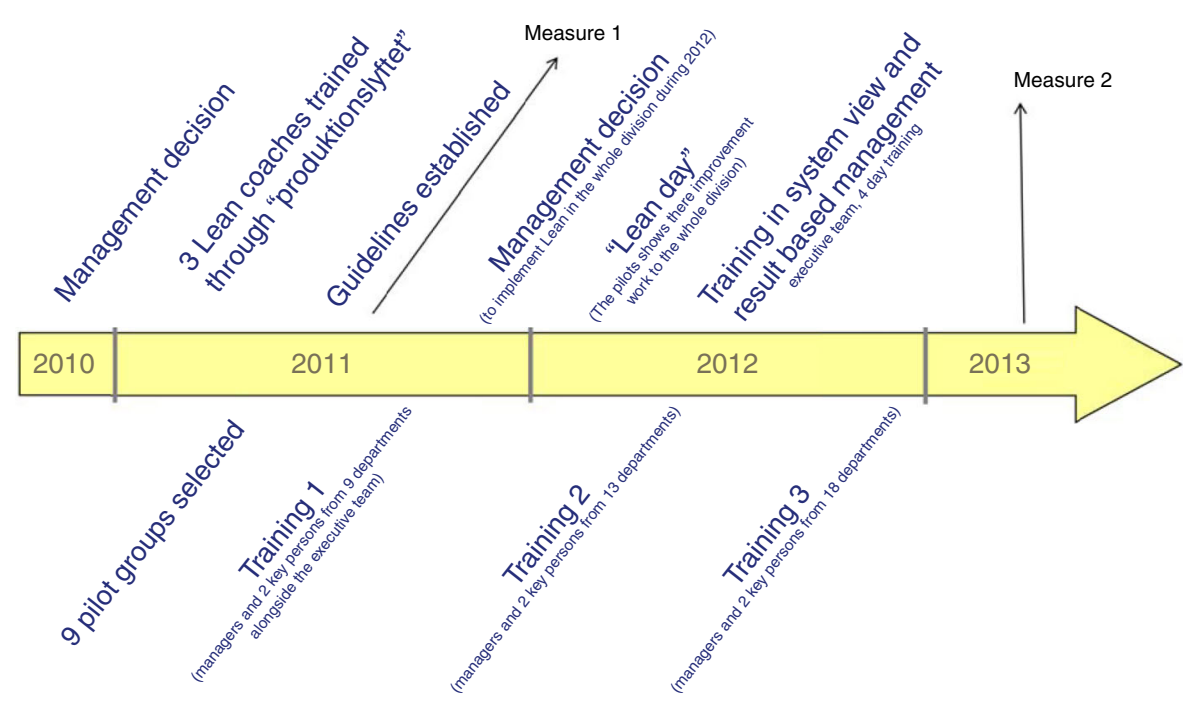


The results from the questionnaires were analyzed using SPSS, mean values were calculated for each dimension at each measurement occasion. In order to test the internal consistency reliability Cronbach's $\alpha$ was calculated for each dimension at each measuring point using the SPSS reliability analysis procedure (Malhotra and Birks, 2000). A value of 0.6 or less is generally considered unsatisfactory (Malhotra and Birks, 2000) as the coefficient tends to increase with the number of items or statements. In order to compare the two measurements, to see if there were any significant changes in results after the 18 months, the SPSS independent sample $t$ test was used. The documents were analyzed by means of document comparisons and consensus discussion in the research group.

\section{Case description}

Sundsvall is a municipality in central Sweden. It has nearly 96,000 inhabitants with an average age of 42 years. The municipal administration, Sundsvalls Kommun, employs 7,000 people. In 2012, Sundsvalls Kommun started to apply lean. Before the entire municipality started to apply lean, the Service and Technical Division decided to start in advance. It is one of the nine divisions in the whole municipality and employs more than 500 people. The Service and Technology Division is divided into four sub units, each with different areas of activity: Addera, Gallant, Drakfastigheter and Stab. The executive group for the Service and Technical division decided in September 2010 that they would start to implement lean. The reason for this decision was demands from politicians and management for higher customer satisfaction and quality as well as cost-effectiveness. They began by working with the frames and educating lean coaches. The leaders went to several lecturers in lean and a four day basic course in lean. The lean coaches worked with the leaders in regards to the lean principles on several occasions. In April 2011 they distributed an A5 poster to all co-workers explaining the attitudes forming the foundation of the lean house, a short description of what lean is and a description of their route to success. They also designed a plan of action where they specified "What" and "How" they should work with the lean implementation. A communication plan was designed and distributed in June 2011. The organization was asked whether anyone wanted to become pilots and to be first to start with the lean implementation and some of the sub-units decided to do this. The pilots started with the lean training and activities and were intended to be role models for the others. Follow on activities are shown in Figure 4.

\section{The measuring}

The management for the municipal division wanted to measure if their lean improvement work produced any effect on a number of different aspects. They therefore decided to measure before the initiative was deployed as well as after working with lean for a while. This would provide a starting point when starting to work with the whole division. As they saw their lean implementation as a whole, one aspect they wanted to measure was important values such as leadership commitment and participation of everybody. They also wanted to measure the co-workers' perceived health. The choice for this measurement fell on the previously presented measurement approach which assessed health-related QM and co-workers' perception of their health (Lagrosen et al., 2012).

The measuring of the starting points was conducted during the Summer of 2011 (measure 1) and it was the lean coaches who had the responsibility to distribute and collect the questionnaire in the different parts of the organization. That was carried out during the ordinary staff meetings at the different sub-units. A total of 397 co-workers answered the questionnaire which gave a response rate of 79 percent. The follow up (measure 2) was carried out in the Spring of 2013. This measurement was conducted via the same questionnaire but this time it was web-based. A total of 281 co-workers answered the questionnaire which this time gave a response rate of 60 percent. All co-workers at 
IJWHM 10,3

\section{8}

the municipal division working at the time the questionnaire was distributed were given the chance to answer. The comparison of means between the two measurement occasions was done on a group level since no matching on individual level was possible due to confidentiality issues as well as co-workers leaving and others joining the division. The results were presented to the management and compiled in two reports that were distributed to the municipality.

\section{Results}

The results of the internal consistency reliability analysis are presented in Table I. The results of the Cronbach's $\alpha$ analysis show that the internal consistency reliability is satisfactory as all dimensions in both measurement is over 0.6.

The results from the independent sample $t$ test show values between 0.25 and 0.69 (equal variance assumed) and between 0.26 and 0.68 (equal variance not assumed) so the difference between measurement one and two is not statistically significant. Even though the difference is not statistically significant it is still of interest to describe the changes between the two measurements. The mean values in both measure one and measure two are on quite a high level on a seven agreement scale, they span between 4.57 and 5.74 . The majority of co-workers actually think that the QM values "Leadership Commitment" and "Participation of Everybody" already permeate the organization. They also think they are healthy as the mean value for the health index is over 5.5 in both measures.

The effect the lean initiative had on the QM values "Leadership Commitment" and "Participation of Everybody" and health among the co-workers is presented below. The mean values from measuring the starting points are compared with the mean values from the measuring after 18 months of lean activities. Table II presents the mean value for each dimension of the QM value "Leadership Commitment" for measurement one and measurement two, on a seven-point agreement scale. The mean value of the underlying dimension of the QM value "Participation of Everybody" for measurements one and two are presented in Table III. In Table IV, the comparison between the mean values in measurements one and two of the health index is presented.

\begin{tabular}{lcc}
\hline & & Cronbach's $\alpha$ \\
Dimensions & Measurement 1 & Measurement 2 \\
\hline Empathy & 0.831 & 0.871 \\
Presence and communication & 0.758 & 0.789 \\
Integrity & 0.870 & 0.874 \\
Continuity & 0.692 & 0.691 \\
Development & 0.890 & 0.906 \\
Influence & 0.691 & 0.724 \\
Being informed & 0.815 & 0.865 \\
Health index & 0.811 & 0.861 \\
\hline
\end{tabular}

Table I.

The results of the internal consistency reliability analysis of the measured dimensions at measurement 1 and 2

\begin{tabular}{lcccccccc}
\hline & \multicolumn{1}{c}{ Empathy } & \multicolumn{2}{c}{ Presence and communication } & \multicolumn{2}{c}{ Integrity } & \multicolumn{2}{c}{ Continuity } \\
\hline Measurement & 1 & 2 & 1 & 2 & 1 & 2 & 1 & 2 \\
Municipal division & 4.60 & 4.84 & 4.58 & 4.74 & 4.57 & 4.83 & 5.08 & 5.14 \\
Changes in mean value & \multicolumn{2}{c}{+0.24} & & +0.16 & & \multicolumn{2}{c}{+0.26} & \multicolumn{2}{c}{+0.06}
\end{tabular}

Table II.

The dimensions within the QM value "leadership commitment” 
The comparison shows that the mean has changed positively for all of the dimensions of the QM value "Leadership Commitment." Although the changes are not significant, the health-related QM value "Leadership Commitment" still permeates the organization to a relatively high extent after 18 months of lean implementation. The consistent relatively high mean value regarding the dimension "Empathy" and "Integrity," implies that the managers in the organization show awareness and concern and are alert to the needs of the co-workers and understand their situation. The dimensions "Continuity" and "Empathy" are the dimensions that have the highest mean values. This implies that the managers in the organization stay in the same position for a long time and also that the managers show awareness and concern and are alert to the needs of the co-workers and understand their situation (Lagrosen et al., 2010).

All the dimensions of the QM value "Participation of Everybody" also have consistent high mean scores which indicate that the co-workers still think they are offered both skills and personal development, have the possibility to influence their own work situation and are getting enough information (Lagrosen et al., 2010).

The health index which measures the co-workers' perception of their health has a reduced mean value when measurements one and two are compared. However the mean value is rather high on a seven-point agreement scale and shows that the co-workers still think they are healthy.

\section{Conclusion and discussion}

We can conclude that, when measuring the effects a lean initiative has on values, a period of 18 months might be too short, if significance changes are expected. None the less, even though the time is short between the first and the second measurement, the results can be a way of monitoring the development of these softer values (Louise, 1996). Something that is equally important is to see if there have been any major changes, as a way of keeping the work with building a new culture alive and in focus. This is in line with Liker (2004) who established that implementing lean needs a deep cultural transformation which makes the lean initiative a long-time commitment. According to Emiliani (1998), it normally takes five to ten years to practice sustained lean behaviors, so the time between the measurements can be considered short since changing a culture and the value base often takes longer than 18 months Bhasin and Burcher (2006), also agree that it takes time: they argue a minimum need of three to five years to start practicing a lean philosophy. For a fruitful implementation lean need to be regarded as a long-term journey and the organization needs to make several cultural changes (Bhasin and Burcher, 2006). As McNabb and Sepic (1995) underline, it is important to measure

\begin{tabular}{|c|c|c|c|c|c|c|}
\hline \multirow[b]{2}{*}{ Measurement } & \multicolumn{2}{|c|}{ Development } & \multicolumn{2}{|c|}{ Influence } & \multicolumn{2}{|c|}{ Being informed } \\
\hline & 1 & 2 & 1 & 2 & 1 & 2 \\
\hline Municipal division & 4.74 & 4.88 & 5.12 & 5.17 & 4.62 & 4.77 \\
\hline Changes in mean value & \multicolumn{2}{|c|}{+0.14} & \multicolumn{2}{|c|}{+0.05} & \multicolumn{2}{|c|}{+0.15} \\
\hline
\end{tabular}

Notes: The results from the two measurements of the dimensions within the QM value "participation of everybody"
Effects of lean on

health-related QM values

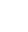


IJWHM 10,3 before the quality initiative starts, i.e. the starting points. As establishing a new or modified organizational culture is a long-term process, it is central not to have too high expectations of the measurement results too soon. Instead the measurement of the soft values can be a way of measuring if the organization is on the right track as many authors emphasize shared value as a prerequisite for successful quality improvement work.

The effects on the health-related QM values; "Leadership Commitment" and "Participation of everybody" in this study showed that the values still permeated the organization to a relatively high extent and that no statistical differences can be shown between the two measurement points. This can be interpreted positively as it shows that the health-related QM values and the co-workers' perceived health are not affected negatively by the lean initiative. This also reinforces the assumption that the long-term mindset is important and that more measurement points are needed in the future in order to monitor the effects. Looking forward when it comes to the case studied, and since lean had not been applied in the whole organization at the time the second measurement was carried out, it would be interesting to keep measuring the softer values when monitoring the application of lean in the municipality. This should be done in order to see if a broader application of lean has affected the measurements in any direction.

It would also be interesting to monitor soft values in different kinds of organizations, especially with the focus on perceived health since there are some concerns that lean can lead to more stressful work situations if it is not applied in the "right" way (Koukoulaki, 2014). This measuring could also give us a hint as to whether the health-related QM values are affected when applying lean in an organization. If lean is an initiative deriving from the same roots as TQM (Dahlgaard and Dahlgaard-Park, 2006), applying lean in an organization should affect these values as well as others more related to lean thinking. Even though changing the value base of an organization takes longer than 18 months, the measurement of perceived health could indicate earlier if something is not right. Earlier studies have pointed both to positive and negative effects on co-worker health (Hasle et al., 2012; Bäckström, Lagrosen, and Eriksson, 2014; Bäckström, Ingelsson, and Johansson, 2014). It can then be concluded that the context in which lean is being applied has also affected the results, as Hasle et al. (2012) have already stated. How and why the quality initiative is being applied also affects the outcome (Emiliani, 2010). Since the way of implementing lean affects the outcome as well as co-worker well-being and a value change is important for success, the combination of measuring values and health could be a useful way of monitoring the softer side of a lean initiative.

The results strengthen the assumption that both the soft and the hard side need to be taken into consideration when applying a QM initiative such as lean in an organization. It has been pointed out that a measurement of the soft values is lacking (Ingelsson et al., 2010); however this is important when the efficiency and effectiveness are measured (Radnor and McGuire, 2004). The shared value base or the principles can be one way of measuring the soft values.

As Longoni et al. (2013) suggested, this study has further explored the QM in relation to lean in the respect of how the QM values "Leadership commitment" and "Participation of Everybody" are effected by a lean initiative. However, there has to be a more long-term mindset when QM initiatives such as lean are applied within an organization, something that is also important when it comes to measuring the softer effects as well as interpreting them.

\section{References}

Achanga, P., Shehab, E., Roy, R. and Nelder, G. (2006), "Critical success factors for lean implementation within SMEs”, Journal of Manufacturing Technology Management, Vol. 17 No. 4, pp. 460-471.

Ahmed, M.H. (2013), "Lean transformation guidance: why organisations fail to achieve and sustain excellence through lean improvement", International Journal of Lean Thinking, Vol. 4 No. 1, pp. 31-40. 
Angelis, J., Conti, R., Cooper, C. and Gill, C. (2011), "Building a high-commitment lean culture", Journal of Manufacturing Technology Management, Vol. 22 No. 5, pp. 569-586.

Arnetz, B. (2005), "Subjective indicators as a gauge for improving organisational well-being. An attempt to apply the cognitive activation theory to organisations", Psychoneuroendocrinology, Vol. 30 No. 10, pp. 1022-1026.

Åslund, A., Bäckström, I. and Richardsson, D. (2011), "Managing appreciative leadership to create efficiency organizations and healthy co-workers?", Proceedings of ICQSS 2011, 14th OMOD Conference on Quality and Service Sciences, San Sebastian, August.

Bäckström, I. (2009), "On the relationship between sustainable health and quality management: leadership and organizational behaviours from Swedish organizations", doctoral thesis, Department of Engineering and Sustainable Development, Mid Sweden University, Östersund.

Bäckström, I. and Ingelsson, I. (2015), "Is there a relationship between lean leaders and healthy co-workers?”, Quality Innovation Prosperity, Vol. 19 No. 2, pp. 123-136.

Bäckström, I., Eriksson, L. and Lagrosen, Y. (2012), "A health-related quality management approach to evaluating health promotion activities", International Journal of Quality and Service Sciences, Vol. 4 No. 1, pp. 76-85.

Bäckström, I., Ingelsson, P. and Johansson, C. (2014), "Health related quality management values and key principles of communicative leadership - are they the same?", Quality Innovation Prosperity, Vol. 18 No. 1, pp. 59-72.

Bäckström, I., Ingelsson, P. and Johansson, C. (2016), "How communicative leadership influences co-workers' health - a quality management perspective", International Journal of Quality and Service Sciences, Vol. 8 No. 2, pp. 143-158.

Bäckström, I., Lagrosen, Y. and Eriksson, L. (2014), "Change of the quality management culture through health-promotion activities?”, Total Quality Management \& Business Excellence, Vol. 26 No. 11, pp. 1236-1246.

Beatty, J.R. (2006), "The quality journey: historical and workforce perspectives and the assessment of commitment to quality", International Journal of Productivity and Quality Management, Vol. 1 Nos 1-2, pp. 139-167.

Bhasin, S. and Burcher, P. (2006), "Lean viewed as a philosophy", Journal of Manufacturing Technology Management, Vol. 17 No. 1, pp. 56-72.

Bicheno, J. (2004), The New Lean Toolbox: Towards Fast, Flexible Flow, 3rd ed., PICSIE Books, Buckingham.

Bicheno, J. and Holweg, M. (2009), The Lean Toolbox: The Essential Guide to Lean Transformation, PICSIE Books, Buckingham.

Bolin, M. (2009), "The importance of organizational characteristics for psychosocial working conditions and health", doctoral thesis, Umeå University, Umeå.

Brännmark, M. (2012), "Lean i kommuner och myndigheter: En översikt över existerande empirisk forskningslitteratur", (in Swedish), available at: www.blaljus.nu/sites/default/files/filarkiv/ forskningsoversikt_lean.pdf

Chatman, J.A. and Cha, S.E. (2003), "Leading by leveraging culture", California Management Review, Vol. 45 No. 4, pp. 20-34.

Conti, R., Angelis, J., Cooper, C., Faragher, B. and Gill, C. (2006), "The effects of lean production on workers job stress", International Journal of Operations \& Production Management, Vol. 26 No. 9, pp. 1013-1038.

Dahlgaard, JJJ. and Dahlgaard-Park, S.M. (2006), "Lean production, six sigma quality", TQM and company culture”, The TQM Magazine, Vol. 18 No. 3, pp. 263-281.

Dale, B.G. (2003), Managing Quality, 4th ed., Blackwell Publishing, Oxford.

Docherty, P. (2002), Creating Sustainable Work Systems - Emerging Perspectives and Practice, Taylor \& Francis Ltd, London. 
IJWHM 10,3

Drew, J., McCallum, B. and Roggenhofer, S. (2004), Journey to Lean: Making Operational Change Stick, Palgrave Macmillan, Gordonsville, VA.

Emiliani, B. (2010), Moving Forward Faster: The Mental Evolution from Fake Lean to REAL Lean, The Center for Lean Business Management, LLC, Wethersfield, CT.

Emiliani, M.L. (1998), “Lean behaviors”, Management Decision, Vol. 36 No. 9, pp. 615-631.

Emiliani, M.L. (2005), "Using kaizen to improve graduate business school degree programs", Quality Assurance in Education, Vol. 13 No. 1, pp. 37-52.

Grönfeldt, S. and Strother, J. (2006), Service Leadership: The Quest for Competitive Advantage, SAGE Publications, Thousand Oaks, CA.

Halling, B. and Wijk, K. (2013), "Experienced barriers to lean in Swedish manufacturing and health care", International Journal of Lean Thinking, Vol. 4 No. 2, pp. 43-63.

Hamid, M.R.A., Mustafa, Z., Idris, F., Abdullah, M. and Suradi, N.R.M. (2011), "Measuring value - based productivity: a confirmatory factor analytic (CFA) approach", International Journal of Business and Social Science, Vol. 2 No. 6, pp. 85-93.

Hansson, J. (2003), "Total quality management-aspects of implementation and performance: investigations with a focus on small organisations", Doctoral thesis No. 2003:07, Luleå University of Technology, Luleå.

Harnesk, R. and Abrahamsson, L. (2007), "TQM: an act of balance between contradictions", The TQM Magazine, Vol. 19 No. 6, pp. 531-541.

Hasle, P., Bojesen, A., Jensen, P.L. and Bramming, P. (2012), "Lean and the working environment: a review of the literature", International Journal of Operations \& Production Management, Vol. 32 No. 7, pp. 829-849.

Hendricks, K.B. and Singhal, V.R. (1999), “Don’t count TQM out”, Quality Progress, Vol. 32 No. 4, pp. 35-42.

Hughes, N. (2007), "Is life a balancing act?", Industrial and Commercial Training, Vol. 39 No. 5, pp. 281-284.

Ingelsson, P. (2013), "Creating a quality management culture: focusing on values and leadership. Department of quality technology and management", doctoral thesis, Department of Engineering and Sustainable Development, Mid Sweden University, Östersund.

Ingelsson, P. and Bäckström, I. (2016), "Monitoring co-worker health and lean culture development", Proceedings of the 19th QMOD Conference on Quality and Service Sciences ICQSS 2016, Building a Culture for Quality, Innovation and Sustainability, Rome, September 21-23.

Ingelsson, P., Bäckström, I. and Wiklund, H. (2010), "Measuring the soft sides of TQM and lean", Proceedings of the 13th QMOD International Conference, Quality Management and Organizational Development, Cottbus, August.

Janssen, N., Kant, I.J., Swaen, G.M.H., Janssen, P.P.M. and Scröer, C.A.P. (2003), "Fatigue as a predictor of sickness absence: results from the Maastricht cohort study on fatigue at work", Occupational and Environmental Medicine, Vol. 60 No. S1, pp. 71-76.

Kollberg, B., Dahlgaard, J.J. and Brehmer, P.-O. (2007), "Measuring lean initiatives in health care services: issues and findings", International Journal of Productivity and Performance Management, Vol. 56 No. 1, pp. 7-24.

Koukoulaki, T. (2014), "The impact of lean production on musculoskeletal and psychosocial risks: an examination of sociotechnical trends over 20 years", Applied Ergonomics, Vol. 45 No. 2, pp. 198-212.

Lagrosen, Y. and Bäckström, I. (2005), "Values of TQM and employee health: an exploration and comparison of two manufacturing departments", Proceedings of 8th QMOD International Conference, Quality Management and Organizational Development, Palermo, June.

Lagrosen, Y., Bäckström, I. and Lagrosen, S. (2007), "Quality management and health-a double connection”, International Journal of Quality \& Reliability Management, Vol. 24 No. 1, pp. 49-61. 
Lagrosen, Y., Bäckström, I. and Lagrosen, S. (2010), "The relationship between quality management and health-exploring the underlying dimensions", International Journal of Productivity and Quality Management, Vol. 5 No. 2, pp. 109-123.

Lagrosen, Y., Bäckström, I. and Wiklund, H. (2012), "Approach for measuring health-related quality management”, The TQM Journal, Vol. 24 No. 1, pp. 59-71.

Liker, J.K. (2004), The Toyota Way: 14 Management Principles from the World's Greatest Manufacturer, McGraw-Hill, New York, NY.

Longoni, A., Pagell, M., Johnston, D. and Veltri, A. (2013), "When does lean hurt? - An exploration of lean practices and worker health and safety outcomes", International Journal of Production Research, Vol. 51 No. 11, pp. 3300-3320.

Louise, C. (1996), “Analysing business performance: counting the 'soft' issues", Leadership \& Organization Development Journal, Vol. 17 No. 4, pp. 21-28.

McAdam, R. and Bannister, A. (2001), "Business performance measurement and change management within a TQM framework", International Journal of Operations \& Production Management, Vol. 21 Nos 1/2, pp. 88-107.

McNabb, D.E. and Sepic, F.T. (1995), "Culture, climate, and total quality management: measuring readiness for change”, Public Productivity \& Management Review, Vol. 18 No. 4, pp. 369-385.

Malhotra, N.K. and Birks, D. (2000), Marketing Research: An Applied Approach, European ed., Pearson Education, Harlow.

Marklund, S., Bolin, M. and von Essen, J. (2008), "Can individual health differences be explained by workplace characteristics? - A multilevel analysis", Social Science \& Medicine, Vol. 66 No. 3, pp. 650-662.

Mazzocato, P., Savage, C., Brommels, M., Aronsson, H. and Thor, J. (2010), "Lean thinking in healthcare: a realist review of the literature”, BMJ Quality \& Safety, Vol. 19 No. 5, pp. 376-382.

Motwani, J. (2001), “Critical factors and performance measures of TQM", The TQM Magazine, Vol. 13 No. 4, pp. 229-300.

Nordin, M. and Bolin, M. (2014), "Do sex differences in the association between work exposure and health in the manufacturing industry depend on work context? Results from the WOLF-study", Psychology, Vol. 5 No. 8, pp. 896-907.

O'Reilly, C.A., Chatman, J. and Caldwell, D.F. (1991), "People and organizational culture: a profile comparison approach to assessing person-organization fit", The Academy of Management Journal, Vol. 34 No. 3, pp. 487-516.

Peter, K. and Lanza, G. (2011), "Company-specific quantitative evaluation of lean production methods", Production Engineering, Vol. 5 No. 1, pp. 81-87.

Petersen, K. and Wohlin, C. (2011), "Measuring the flow in lean software development", Software - Practice and Experience, Vol. 41 No. 9, pp. 975-996.

Poksinska, B. (2010), "The current state of lean implementation in health care: literature review", Quality Management in Health Care, Vol. 19 No. 4, pp. 319-329.

Poksinska, B., Swartling, D. and Drotz, E. (2013), "The daily work of lean leaders - lessons from manufacturing and healthcare", Total Quality Management \& Business Excellence, Vol. 24 No. 8, pp. 886-898.

Radnor, Z. and Boaden, R. (2010), "Editorial: lean in public services-panacea or paradox?", Public Money \& Management, Vol. 28 No. 1, pp. 3-7.

Radnor, Z. and McGuire, M. (2004), "Performance management in the public sector: fact or fiction?", International Journal of Productivity and Performance Management, Vol. 53 No. 3, pp. 245-260.

Radnor, Z. and Walley, P. (2008), "Learning to walk before we try to run: adapting lean for the public sector", Public Money \& Management, Vol. 28 No. 1, pp. 13-20.

Radnor, Z., Walley, P., Stephens, A. and Bucci, G. (2006), Evaluation of the Lean Approach to Business Management and Its Use in the Public Sector, Crown, Edinburgh.

Effects of lean on health-related QM values 
IJWHM

10,3

Radnor, Z.J. and Barnes, D. (2007), "Historical analysis of performance measurement and management in operations management", International Journal of Productivity and Performance Management, Vol. 56 Nos 5/6, pp. 384-396.

Saad, M. and Patel, B. (2006), "Benchmarking: an investigation of supply chain performance measurement in the Indian automotive sector", Benchmarking: An International Journal, Vol. 13 Nos 1/2, pp. 36-53.

Shah, R. and Ward, P.T. (2007), "Defining and developing measures of lean production", Journal of Operations Management, Vol. 25 No. 4, pp. 785-805.

Sila, I. and Ebrahimpour, M. (2002), "An investigation of the total quality management survey based research published between 1989 and 2000", International Journal of Quality and Reliability Management, Vol. 19 No. 7, pp. 902-970.

Sinkula, J.M., Baker, W.E. and Noordewier, T. (1997), "A framework for market-based organizational learning: linking values, knowledge, and behavior", Journal of the Academy of Marketing Science, Vol. 25 No. 4, pp. 305-318.

Snyder, K., Ingelsson, P. and Bäckström, I. (2016), "Enhancing the study of lean transformation through organisational culture analysis", International Journal of Quality and Service Sciences, Vol. 8 No. 3, pp. 395-411.

Snyder, K.J., Acker-Hocevar, M. and Snyder, K.M. (2000), Living on the Edge of Chaos: Leading Schools into the Global Age, ASQ Quality Press, Milwaukee, WI.

SOU (2013), Att tänka nytt för att göra nytta - om perspektivskifte i offentlig verksamhet, Slutbetänkande av Innovationsrådet, Stockholm, p. 40, available at: www.regeringen.se/rattsdokument/statensoffentliga-utredningar/2013/06/sou-201340/ (accessed August 18, 2015).

Wolf, K. (2008), "Health and productivity management in Europe", International Journal of Workplace Health Management, Vol. 1 No. 2, pp. 136-144.

Womack, J.P. and Jones, D.T. (2003), Lean Thinking: Banish Waste and Create Wealth in Your Corporation, Free Press Business, London.

Wreder, Å. (2006), How to Create Sustainable Health: Experiences Taken from Swedish Organizations, Luleå University of Technology, Luleå.

Yamamoto, Y. and Bellgran, M. (2010), "Fundamental mindset that drives improvements towards lean production”, Assembly Automation, Vol. 30 No. 2, pp. 124-130.

Zwetsloot, G. and Pot, F. (2004), "The business value of health management", Journal of Business Ethics, Vol. 55 No. 2, pp. 115-124.

Zwetsloot, G.I., van Scheppingen, A.R., Dijkman, A.J., Heinrich, J. and den Besten, H. (2010), "The organizational benefits of investing in workplace health", International Journal of Workplace Health Management, Vol. 3 No. 2, pp. 143-159.

\section{Corresponding author}

Pernilla Ingelsson can be contacted at: pernilla.ingelsson@miun.se

For instructions on how to order reprints of this article, please visit our website:

www.emeraldgrouppublishing.com/licensing/reprints.htm

Or contact us for further details: permissions@emeraldinsight.com 